\title{
MUC2 mRNA detection in peripheral blood and bone marrow of breast cancer patients reveals micrometastasis
}

\author{
Negar Khazan ${ }^{1}$, Ardeshir Ghavamzadeh², Anna S. Boyajyan ${ }^{1}$, Gohar M. Mkrtchyan $^{1}$, \\ Kamran Alimoghaddam ${ }^{2}$, Seyed H. Ghaffari ${ }^{2 *}$ \\ ${ }^{1}$ Institute of Molecular Biology, National Academy of Sciences of the Republic of Armenia, Yerevan, Armenia \\ ${ }^{2}$ Hematology, Oncology and Bone Marrow Transplantation Research Center, Tehran University of Medical Sciences, Tehran, Iran; \\ *Corresponding Author: shghaffari200@yahoo.com
}

Received 12 November 2012; revised 15 December 2012; accepted 28 December 2012

\begin{abstract}
Tumor dissemination to distant organ is the main cause of death. Therefore there is urgent need to set up sensitive methods for early detection of circulating tumor cells (CTCs) and disseminated tumor cells (DTCs) in peripheral blood (PB) and bone marrow (BM) specimens of breast cancer patients. We aim to detect MUC2 mRNA positive cells in PB and BM of breast cancer patients; to relate this to patient relapse. In this study to detect MUC2 mRNA positive cells (tumor marker), PB and BM samples were collected from 50 breast cancer patients after operation and before adjuvant therapy with 20 PB from healthy individuals as negative controls. Chi-square test was used to analyze data. MUC2 mRNA by using Real-time PCR was detected in $9(18 \%)$ of PB and in $10(20 \%)$ of BM samples and none of the healthy individuals. The relapse rate among MUC2-positive patients was significance in BM $(P<0.004)$ and MUC2-positive patients had a shorter disease free survival than the negative patients in BM samples $(p<0.05)$. This study shows MUC2 can be a suitable marker for detection of micrometastasis in breast cancer patients at early stages of cancer.
\end{abstract}

Keywords: Circulating Tumor Cells; Breast Cancer; MUC2; Real-Time PCR; Micrometastasis

\section{INTRODUCTION}

Breast cancer is the leading cause of cancer death and the most frequently diagnosed cancer in females worldwide, in 2008 , it accounted for $23 \%$ of the total new cancer cases and $14 \%$ of the total cancer deaths [1]. Breast cancer is ranked first among malignancies among
Iranian women, with a rough incidence rate of 17.81 [2] comprising $24.4 \%$ of all neoplasms [3] in the year of 2006.

In breast cancer, both hematogenous and lymphatic dissemination of carcinoma cells may occur even in patients with small tumors, so breast cancer is considered a systemic disease. Although the detection of metastasis to axillary lymph nodes is a proven prognostic factor, usually $20 \%-30 \%$ of axillary node negative patients will show a recurrence. Micrometastases, which are undetectable by classical imaging, can contribute to disease relapse; therefore, identification of micrometastases in patients with early-stage breast cancer could have significant impact on deciding treatment strategies and determining prognosis for the patients [4].

Different markers have been used for the molecular detection of bone marrow disseminated tumor cells (DTCs) and peripheral blood circulating tumor cells (CTCs) [5]. The detection of occult micrometastases in bone marrow (BM) identifies the patients most likely at risk of developing systemic breast cancer relapse. These patients most likely benefit from systemic adjuvant therapy. In addition, it should even be feasible to monitor the effect of such treatment [6]. However, the impact of tumor cells in blood or BM still remains controversial. Immunocytochemistry currently remains the gold standard for BM DTC detection, with a sensitivity ranging from 1 DTC in $10^{5}$ to 1 in $10^{6}$ leucocytes [5]. Recently, it has been shown that detection of DTCs or CTCs (with enrichment step) by real-time RT-PCR can predict overall survival of a patient group including metastatic breast cancers [7].

Mucins are high molecular weight glycoproteins found in human epithelial cells. They characterized by high content of O-linked oligosaccharide side chains attached to a serine and threonine-rich peptide core. Mucins are broadly classified structurally into two main classes: membrane-bound mucins (MUC1, MUC3A, MUC3B, 
MUC4, MUC12, MUC13, MUC15, MUC16, MUC17, and MUC20) and secreted or gel-forming mucins (MUC2, MUC5AC, MUC5B, MUC6, MUC7, MUC8 and MUC19) [8]. Mucins have a central role as cell-surface receptors and conduct signals in response to external stimuli and cause cellular responses that include differentiation, proliferation, apoptosis and secretion of specialized cellular products. Mucins also, have a role in the pathogenesis of some cancers; especially adenocarcinomas [9].

MUC2 is one of the key proteins in protecting and lubricating epithelial surfaces by producing the mucus. It is the main secretory glycoprotein expressed abundantly by intestinal and airway epithelium [10]. Between the secreted mucins, MUC2 has been related to inflammation and cancer. Functionally, MUC2 suppresses inflammation in the intestinal tract and so inhibits the development of intestinal tumors [11]. The expression of MUC2 protein is a common feature of all mucinous carcinomas derived from different organs including breast, colon and prostate [12]. Therefore it may act as a potential prognostic factor. MUC2 expression is associated with aggressive tumor behavior in other types of invasive and intraductal carcinomas of the breast [12-14]. Furthermore, recent study by RT-PCR method has showed that mucins including MUC2, MUC3, MUC5B, MUC6 and MUC7 are differentially expressed transcriptionally in breast cancer cells [15]. This is the first study to detect MUC2 mRNA in PB and BM of patients with breast cancer using QRT-PCR method.

\section{PATIENTS AND METHODS}

\subsection{Patient's Sample}

Bone marrow aspirates and Peripheral blood samples were obtained from 50 patients with histologic diagnosis of ductal breast cancer at different stages. All patients were screened for metastases by conventional staging. Among fifty patients with breast cancer enrolled in this study, there was 1 male and 49 females with a median age of 45 years (range: 28 to 67 years). The patients underwent a modified radical mastectomy or lumpectomy with breast conserving surgery. In this study 48 patients had confirmed primary breast cancer and 2 with metastases. Our study was approved by the ethical review board of the Shariati Hospital, School of Medicine, Tehran University of Medical Sciences, Iran. An informed consent was obtained from all patients entered into the project. $10 \mathrm{ml}$ of Peripheral blood and $5 \mathrm{ml}$ of Bone marrow were collected in EDTA anticoagulant and were quickly sent to the laboratory. Additionally, peripheral blood cells of 20 healthy individuals were taken in the same conditions from healthy donors. Mononuclear cells (MNC) were separated by density-gradient centrifugation through Ficoll and washed several time with PBS. Total RNA was extracted from peripheral blood and bone marrow cells, using a Tri pure Isolation Reagent (Roche) according to the manufacturer's instructions.

\subsection{Quantitative Real-Time RT-PCR}

The quantity of RNA samples was assessed spectrophotometrically using Nanodrop ${ }^{\mathrm{TM}}$ ND-1000 (Nanodrop Technologies, Wilmington, Delaware, USA). Then $1 \mu \mathrm{g}$ of extracted RNA was reverse transcribed into cDNA using the Prime Script ${ }^{\mathrm{TM}}$ RT reagent kit (Takara Bio) according to the manufacture's specifications. Quantitative real-time RT-PCR was performed on an Applied Bio systems Step One Plus ${ }^{\mathrm{TM}}$ system instrument using Preci$\operatorname{sion}^{\mathrm{TM}} 2 \mathrm{X}$ q PCR Master mix (Primer design). master $\operatorname{mix}(10 \mu \mathrm{l}), 2 \mu \mathrm{l}$ of cDNA samples, $0.5 \mu \mathrm{l}$ of forward and reverse primers $(10 \mathrm{pmol})$ and $7 \mu \mathrm{l}$ of nuclease-free water (Qiagen, Hilden, Germany) were mixed to conduct PCR in a $20 \mu \mathrm{l}$ of reaction volume. The thermal cycling conditions were: $10 \mathrm{~min}$ at $95^{\circ} \mathrm{C}$ (initial activation), 40 cycles including $10 \mathrm{sec}$ at $95^{\circ} \mathrm{C}$ and $30 \mathrm{sec}$ at $60^{\circ} \mathrm{C}$. The sequences of primers are listed in Table 1. Hypoxanthine phosphoribosyl transferase (HPRT) was used as a normalizer and the fold change in expression of each target mRNA relative to HPRT was calculated based on $2^{-\Delta \Delta c t}$ comparative expression method [16].

\subsection{Statistical Analysis}

Chi-square test was used to examine the relationship between presences of tumor cells and relapse of disease and also between tumor cells and clinicopathological factors. Disease-free survival (DFS) defined as the time from study entry until the day of the first evidence of disease recurrence. The Kaplan-Meier method was used to estimate DFS curve, and the log-rank test was used to compare the curves. Statistical analysis was performed by SPSS (Version 15). P-Values less than 0.05 were considered significant.

Table 1. Nucleotide sequences of the primers used for real-time PCR.

\begin{tabular}{cccc}
\hline Gene & Accession number & Primers (5'-3') & Size (bp) \\
\hline HPRT & NM_000194 & $\begin{array}{c}\text { CCTGGCGTCGTGATTAGTGAT } \\
\text { AGACGTTCAGTCCTGTCCATAA }\end{array}$ & 131 \\
MUC2 & NM_002457 & $\begin{array}{c}\text { TCCATCCTGCTGACCATCAA } \\
\text { GTAGGCATCGCTCTTCTCAATGA }\end{array}$ & 126 \\
\hline
\end{tabular}




\section{RESULTS}

\subsection{MUC2 mRNA Positive Cells in Peripheral Blood and Bone Marrow Samples}

To evaluate the potential utility of MUC2 gene mRNA detection in the identification of disseminated and circulating breast cancer cells, we have studied the MUC2 mRNA in breast cancer peripheral blood and bone marrow samples. We did not see any MUC2 mRNA in 20 healthy individuals, but in 9 (18\%) PB samples and 10 (20\%) BM samples of patients, MUC2 mRNA was detected. The correlation between BM and PB samples was not significant. In three patients MUC2 was detected in their PB and BM. Figure 1 shows relative MUC2 mRNA level in $\mathrm{PB}, \mathrm{BM}$ and control group of breast cancer patients. The MUC2 level was increased in PB and BM of patients in comparison with the control group.

\subsection{MUC2 mRNA Positive Cells and Clinicopathological Factors}

We have examined the correlation between MUC2 mRNA positive cells and the patient's clinicopathological characteristics. After a median follow-up period of 28 months (range: 4 to 50 months), 15 patients (30\%) had developed disease recurrence. MUC2 mRNA has been observed in $3(20 \%)$ PB samples of relapsed groups and 7 (46\%) BM samples. Clinical relapses were significantly higher in MUC2-positive patients, and MUC2 mRNA level was statistically significant in BM samples of patients who relapsed (Table 2). In addition, as illustrated in Figure 2, MUC2 positive patients had a significantly shorter DFS than the negative patients in bone marrow samples no peripheral blood $(\mathrm{p}<0.05)$. There was no statistically significant correlation between mRNA MUC2 + patients and other clinicopathological characteristics (Table 3).

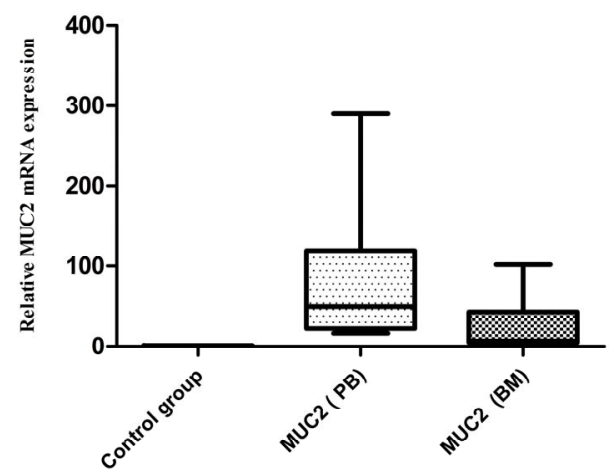

Figure 1. Relative MUC2 level in $\mathrm{PB}, \mathrm{BM}$ and control group of $\mathrm{BC}$ patients. No expression was detected in control group. 9 (18\%) and 10 (20\%) of breast cancer PB and BM samples were positive respectfully for MUC2 mRNA.
Table 2. MUC2 + patients who relapsed in comparison to patients without relapse.

\begin{tabular}{lcccc}
\hline \multirow{2}{*}{$\begin{array}{c}\text { Tumor } \\
\text { marker }\end{array}$} & Sample & \multicolumn{2}{c}{ Total patients $(\mathrm{N}=50)$} & P-value \\
\cline { 3 - 4 } & & $\begin{array}{c}\text { Relapse } \\
\mathrm{N}=15\end{array}$ & $\begin{array}{c}\text { No relapse } \\
\mathrm{N}=35\end{array}$ & \\
\hline \multirow{2}{*}{ MUC2 } & PB & $3(20 \%)$ & $6(17 \%)$ & 0.7 \\
& BM & $7(46 \%)$ & $3(9 \%)$ & 0.004 \\
\hline
\end{tabular}

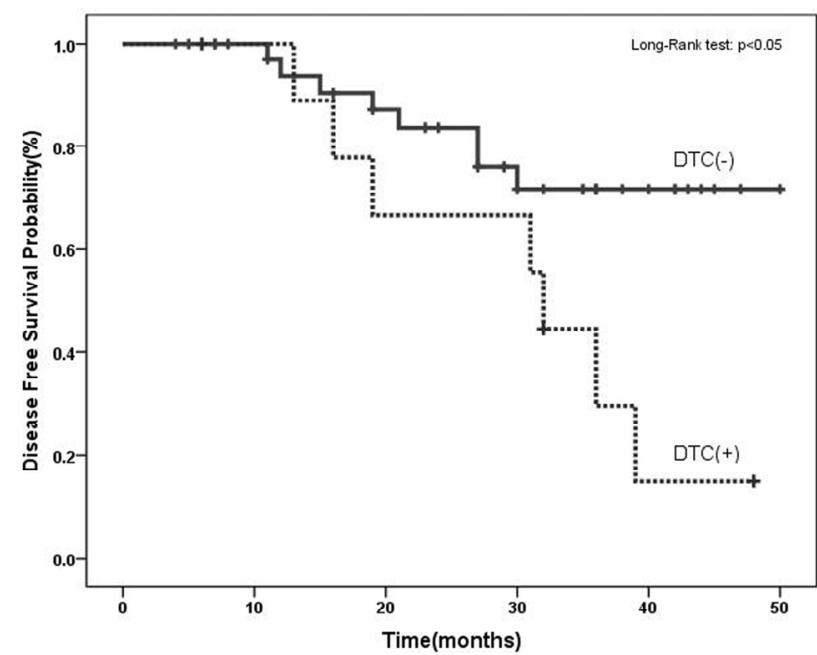

Figure 2. Disease-free survival in breast cancer patients based on the molecular detection of DTCs using MUC2 mRNA before adjuvant therapy. MUC2 positive patients had a significantly shorter DFS than negative patients.

\section{DISCUSSION}

In clinic, the most prognostic information about breast cancer is provided by pathological staging. Nevertheless, about $20 \%$ - $30 \%$ of patients with a favorable prognosis relapse within 5 years and many patients with poor prognostic factors will survive for more than 10 years [17]. So, there is a necessary need for more accurate prognostic factors. Detection of DTCs in bone marrow and CTCs in peripheral blood are promising new parameters, in this context. One of the main confrontations in the diagnosis and therapy of breast cancer is the restricted sensitivity of the existing techniques for the early detection and monitoring of tumors [5]. Real-Time PCR is a specific and sensitive technique for detecting occult tumor cells in peripheral blood and bone marrow of breast cancer patients $[7,18]$. This study has investigated the MUC2 mRNA positive cells and prognostic value of that in breast cancer cases using real time RT-PCR.

The high copy number of MUC1 mRNAs in bone marrow has showed a significantly higher risk of recurrence [19]. Although, MUC1 expression has been seen in most cancer patients; however, expression of MUC1 in control group demands the setting of the cut-off value. In this study, the transcript of MUC2 was not detected in 
Table 3. MUC2 mRNA expression in peripheral and bone marrow samples of breast cancer patients: correlation with lymph node status, tumor size, estrogen and progesterone receptor, Her-2/neu, relapse and vascular invasion.

\begin{tabular}{|c|c|c|c|c|c|c|}
\hline \multirow[b]{2}{*}{ Characteristics } & \multicolumn{3}{|c|}{ Peripheral Blood } & \multicolumn{2}{|c|}{ Bone Marrow } & \multirow[b]{2}{*}{$\mathrm{P}$} \\
\hline & All patients No (\%) & MUC2 mRNA + No (\%) & $\mathrm{P}$ & All patients No (\%) & MUC2 mRNA + No (\%) & \\
\hline \multicolumn{7}{|l|}{ Patients enrolled } \\
\hline Age, year & $50(100)$ & $9(18)$ & & $50(100)$ & $10(20)$ & \\
\hline Median & 45 & 40 & & 45 & 45 & \\
\hline Range & $28-67$ & $30-67$ & & $28-67$ & $30-64$ & \\
\hline \multicolumn{7}{|l|}{ Lymph node } \\
\hline Positive & $20(40)$ & $4(20)$ & & $21(42)$ & $4(20)$ & \\
\hline Negative & $19(38)$ & $2(10)$ & 0.2 & $19(38)$ & $2(10)$ & 0.3 \\
\hline Unknown & $11(22)$ & & & $10(20)$ & & \\
\hline \multicolumn{7}{|l|}{ Tumor size } \\
\hline$>5 \mathrm{~cm}$ & $7(14)$ & $2(28)$ & & $7(14)$ & $1(14)$ & \\
\hline$<5 \mathrm{~cm}$ & $36(72)$ & $4(11)$ & 0.2 & $36(72)$ & $6(17)$ & 0.6 \\
\hline Unknown & $7(14)$ & & & $7(14)$ & & \\
\hline \multicolumn{7}{|l|}{ Estrogen r. } \\
\hline Positive & $31(62)$ & $5(16)$ & & $31(62)$ & $4(13)$ & \\
\hline Negative & $16(32)$ & $1(6)$ & 0.2 & $16(32)$ & $3(19)$ & 0.4 \\
\hline Unknown & $3(6)$ & & & $3(6)$ & & \\
\hline \multicolumn{7}{|l|}{ Progesterone $r$. } \\
\hline Positive & $30(60)$ & $6(20)$ & & $30(60)$ & $5(17)$ & \\
\hline Negative & $18(36)$ & $1(6)$ & 0.1 & $18(36)$ & $3(17)$ & 0.6 \\
\hline Unknown & $2(4)$ & & & $2(4)$ & & \\
\hline \multicolumn{7}{|l|}{ Her-2/neu } \\
\hline Positive & $25(50)$ & $3(12)$ & & $25(50)$ & $4(16)$ & \\
\hline Negative & $19(38)$ & $3(16)$ & 0.4 & $19(38)$ & $4(21)$ & 0.4 \\
\hline Unknown & $7(14)$ & & & $6(12)$ & & \\
\hline \multicolumn{7}{|l|}{ Relapse } \\
\hline Positive & $15(30)$ & $3(20)$ & & $15(30)$ & $7(46)$ & \\
\hline Negative & $35(70)$ & $6(17)$ & 0.7 & $35(70)$ & $3(9)$ & 0.004 \\
\hline \multicolumn{7}{|l|}{ Vascular invasion } \\
\hline Positive & $26(52)$ & $3(11)$ & & $26(52)$ & $6(23)$ & \\
\hline Negative & $9(18)$ & $2(22)$ & 0.4 & $9(18)$ & $1(11)$ & 0.4 \\
\hline Unknown & $15(30)$ & & & $15(30)$ & & \\
\hline
\end{tabular}

any of healthy peripheral blood samples. This result indicates high specificity of MUC2 for detection of CTCs and confirmed previous study [15].

It has been reported that breast cancer patients with MUC2 positive tumors had a significantly shorter survival (49 months) compared to those without MUC2 mRNA positive tumors (75 months) [13]. Previous study shows that MUC2 mRNA detection has an inverse association with lymph node stage, vascular invasion, and estrogen receptor status [12]. We saw that DTCs positive patients according to MUC2 mRNA had shorter DFS than the negative patients, but in other clinicopathological factors we did not see any association.

In this study, seven of BM MUC2 positive patients experienced recurrence during 4 years of follow up, in addition, among the relapsed patients; three patients were
MUC2 positive both in PB and BM primary samples. In this study the correlation between the detection of MUC2 mRNA positive cells by real-time PCR in peripheral blood and bone marrow was not significant. Similar observations have been reported by other investigators who evaluated the presence of CK19-positive cells in the peripheral blood and bone marrow [20]. In contrast other studies report the strong correlation between the detection of CK-19 mRNA positive cells by real-time PCR in peripheral blood and bone marrow [21-24]. The lack of a complete concordance between the detection of markerpositive CTCs and DTCs could be related in some extend to the fact that the presence of occult tumor cells in PB is rare and transient events and therefore their evaluation is greatly influenced by sampling volume and time. In addition, only a subpopulation of CTCs has ability to home 
in distant organs such as the bone marrow [23]. Differences in the assays used for the detection could be also a reason of these discrepancies [25]. Nevertheless; the combined positivity for CTC and DTC was associated with a very poor prognosis [24]. Some previous studies reported that the prognostic significance of detection of DTCs in bone marrow was inferior to the detection of CTCs in blood [7,24], but some others not [21]. In this study $33 \%$ and $70 \%$ of MUC2 related CTCs and DTCs positive samples, respectively, showed recurrence; although, the prognostics importance of CTCs was not significant, these results are comparable to $27.5 \%$ [21] $12.8 \%$ [26] and $30 \%$ [27] predictability of CK-19 positive of CTCs and rather than $27.4 \%$ [21] and $29 \%$ [28] of DTCs in previous reports. It seems that detection of MUC2-positive DTC could be potentially useful in the prognosis of patients with a doubted diagnosis of $\mathrm{BC}$ [13].

As far as we are aware, this article is the first report of MUC2 mRNA detection in PB and BM of patients with breast cancer using QRT-PCR method. The main finding of the present study is the correlation between tumor cell presence in the BM and recurrence of disease. We found statistically significant correlation between existence of MUC2 mRNA positive cells in bone marrow samples and relapse of patients during 4 years of follow up (p $<$ 0.004). This analysis offers a simple tool for the early detection of micrometastatic tumor cells and may be potentially useful in the prognosis of patients in breast cancer patients who are in primary stage of their disease.

\section{ACKNOWLEDGEMENTS}

This work was supported by a grant from Hematology, Oncology and stem cell therapy, Tehran University of Medical Sciences, Tehran, Iran.

\section{REFERENCES}

[1] Jemal, A., Bray, F., Center, M.M., Ferlay, J., Ward, E. and Forman, D. (2011) Global cancer statistics. CA: Cancer Journal for Clinicians, 61, 69-90. doi:10.3322/caac.20107

[2] Mousavi, S.M., Gouya, M.M., Ramazani, R., Davanlou, M., Hajsadeghi, N. and Seddighi, Z. (2009) Cancer incidence and mortality in Iran. Annals of Oncology, 20, 556-563. doi:10.1093/annonc/mdn642

[3] Harirchi, I., Kolahdoozan, S., Karbakhsh, M., Chegini, N., Mohseni, S.M., Montazeri, A., Momtahen, A.J., Kashefi, A. and Ebrahimi, M. (2011) Twenty years of breast cancer in Iran: Downstaging without a formal screening program. Annals of Oncology, 22, 93-97. doi:10.1093/annonc/mdq303

[4] Heimann, R. and Hellman, S. (2000) Clinical progression of breast cancer malignant behavior: What to expect and when to expect it. Journal of Clinical Oncology, 18, 591599.
[5] Vincent-Salomon, A., Bidard, F.C. and Pierga, J.Y. (2008) Bone marrow micrometastasis in breast cancer: Review of detection methods, prognostic impact and biological issues. Journal of Clinical Pathology, 61, 570-576. doi:10.1136/jep.2007.046649

[6] Slade, M.J., Singh, A., Smith, B.M., Tripuraneni, G., Hall, E., Peckitt, C., Fox, S., Graham, H., Luchtenborg, M., Sinnett, H.D., Cross, N.C. and Coombes, R.C. (2005) Persistence of bone marrow micrometastases in patients receiving adjuvant therapy for breast cancer: Results at 4 years. International Journal of Cancer, 114, 94-100. doi:10.1002/ijc.20655

[7] Benoy, I.H., Elst, H., Philips, M., Wuyts, H., Van Dam, P., Scharpe, S., Van Marck, E., Vermeulen, P.B. and Dirix, L.Y. (2006) Real-time RT-PCR detection of disseminated tumour cells in bone marrow has superior prognostic significance in comparison with circulating tumour cells in patients with breast cancer. British Journal of Cancer, 94, 672-680.

[8] Mukhopadhyay, P., Chakraborty, S., Ponnusamy, M.P., Lakshmanan, I., Jain, M. and Batra, S.K. (2011) Mucins in the pathogenesis of breast cancer: Implications in diagnosis, prognosis and therapy. Biochimica et Biophysica Acta, 1815, 224-240.

[9] Hollingsworth, M.A. and Swanson, B.J. (2004) Mucins in cancer: Protection and control of the cell surface. Nature Reviews Cancer, 4, 45-60. doi:10.1038/nrc1251

[10] Gum Jr., J.R., Hicks, J.W., Toribara, N.W., Siddiki, B., and Kim, Y.S. (1994) Molecular cloning of human intestinal mucin (MUC2) cDNA. Identification of the amino terminus and overall sequence similarity to preprovon Willebrand factor. Journal of Biological Chemistry, 269, 2440-2446.

[11] Kufe, D.W. (2009) Mucins in cancer: Function, prognosis and therapy. Nature Reviews Cancer, 9, 874-885. doi:10.1038/nrc2761

[12] Rakha, E.A., Boyce, R.W., Abd El-Rehim, D., Kurien, T., Green, A.R., Paish, E.C., Robertson, J.F. and Ellis, I.O. (2005) Expression of mucins (MUC1, MUC2, MUC3, MUC4, MUC5AC and MUC6) and their prognostic significance in human breast cancer. Modern Pathology, 18, 1295-1304. doi:10.1038/modpathol.3800445

[13] Walsh, M.D., McGuckin, M.A., Devine, P.L., Hohn, B.G., and Wright, R.G. (1993) Expression of MUC2 epithelial mucin in breast carcinoma. Journal of Clinical Pathology, 46, 922-925. doi:10.1136/jcp.46.10.922

[14] Diaz, L.K., Wiley, E.L. and Morrow, M. (2001) Expression of epithelial mucins Muc1, Muc2, and Muc3 in ductal carcinoma in situ of the breast. Breast Journal, 7, 40-45. doi:10.1046/j.1524-4741.2001.007001040.x

[15] Berois, N., Varangot, M., Sonora, C., Zarantonelli, L., Pressa, C., Lavina, R., Rodriguez, J.L., Delgado, F., Porchet, N., Aubert, J.P. and Osinaga, E. (2003) Detection of bone marrow-disseminated breast cancer cells using an RT-PCR assay of MUC5B mRNA. International Journal of Cancer, 103, 550-555. doi:10.1002/ijc. 10853

[16] Schmittgen, T.D. and Livak, K.J. (2008) Analyzing realtime PCR data by the comparative CT method. Nature Protocols, 3, 1101-1108. doi:10.1038/nprot.2008.73 
[17] Braun, S., Vogl, F.D., Naume, B., Janni, W., Osborne, M.P., Coombes, R.C., Schlimok, G., Diel, I.J., Gerber, B., Gebauer, G., Pierga, J.Y., Marth, C., Oruzio, D., Wiedswang, G., Solomayer, E.F., Kundt, G., Strobl, B., Fehm, T., Wong, G.Y., Bliss, J., Vincent-Salomon, A. and Pantel, K. (2005) A pooled analysis of bone marrow micrometastasis in breast cancer. The New England Journal of Medicine, 353, 793-802. doi:10.1056/NEJMoa050434

[18] Mitas, M., Mikhitarian, K., Walters, C., Baron, P.L., Elliott, B.M., Brothers, T.E., Robison, J.G., Metcalf, J.S., Palesch, Y.Y., Zhang, Z., Gillanders, W.E. and Cole, D.J. (2001) Quantitative real-time RT-PCR detection of breast cancer micrometastasis using a multigene marker panel. International Journal of Cancer, 93, 162-171. doi:10.1002/ijc.1312

[19] Nogi, H., Takeyama, H., Uchida, K., Agata, T., HoriguchiYamada, J. and Yamada, H. (2003) Detection of MUC1 and keratin 19 mRNAs in the bone marrow by quantitative RT-PCR predicts the risk of distant metastasis in breast cancer patients. Breast Cancer, 10, 74-81. doi:10.1007/BF02967629

[20] Ismail, M.S., Wynendaele, W., Aerts, J.L., Paridaens, R., Gaafar, R., Shakankiry, N., Khaled, H.M., Christiaens, M.R., Wildiers, H., Omar, S., Vandekerckhove, P. and Van Oosterom, A.T. (2004) Detection of micrometastatic disease and monitoring of perioperative tumor cell dissemination in primary operable breast cancer patients using real-time quantitative reverse transcription-PCR. Clinical Cancer Research, 10, 196-201. doi:10.1158/1078-0432.CCR-0515-2

[21] Daskalaki, A., Agelaki, S., Perraki, M., Apostolaki, S., Xenidis, N., Stathopoulos, E., Kontopodis, E., Hatzidaki, D., Mavroudis, D. and Georgoulias, V. (2009) Detection of cytokeratin-19 mRNA-positive cells in the peripheral blood and bone marrow of patients with operable breast cancer. British Journal of Cancer, 101, 589-597. doi:10.1038/sj.bjc.6605183

[22] Pierga, J.Y., Bonneton, C., Vincent-Salomon, A., de Cremoux, P., Nos, C., Blin, N., Pouillart, P., Thiery, J.P. and Magdelenat, H. (2004) Clinical significance of immunocytochemical detection of tumor cells using digital microscopy in peripheral blood and bone marrow of breast cancer patients. Clinical Cancer Research, 10, 1392-1400. doi:10.1158/1078-0432.CCR-0102-03
[23] Muller, V., Stahmann, N., Riethdorf, S., Rau, T., Zabel, T., Goetz, A., Janicke, F. and Pantel, K. (2005) Circulating tumor cells in breast cancer: Correlation to bone marrow micrometastases, heterogeneous response to systemic therapy and low proliferative activity. Clinical Cancer Research, 11, 3678-3685. doi:10.1158/1078-0432.CCR-04-2469

[24] Wiedswang, G., Borgen, E., Schirmer, C., Karesen, R., Kvalheim, G., Nesland, J.M. and Naume, B. (2006) Comparison of the clinical significance of occult tumor cells in blood and bone marrow in breast cancer. International Journal of Cancer, 118, 2013-2019. doi:10.1002/ijc.21576

[25] Schoenfeld, A., Kruger, K.H., Gomm, J., Sinnett, H.D., Gazet, J.C., Sacks, N., Bender, H.G., Luqmani, Y. and Coombes, R.C. (1997) The detection of micrometastases in the peripheral blood and bone marrow of patients with breast cancer using immunohistochemistry and reverse transcriptase polymerase chain reaction for keratin 19 . European Journal of Cancer, 33, 854-861. doi:10.1016/S0959-8049(97)00014-2

[26] Stathopoulou, A., Vlachonikolis, I., Mavroudis, D., Perraki, M., Kouroussis, C., Apostolaki, S., Malamos, N., Kakolyris, S., Kotsakis, A., Xenidis, N., Reppa, D. and Georgoulias, V. (2002) Molecular detection of cytokeratin19-positive cells in the peripheral blood of patients with operable breast cancer: evaluation of their prognostic significance. Journal of Clinical Oncology, 20, 3404-3412. doi:10.1200/JCO.2002.08.135

[27] Ignatiadis, M., Xenidis, N., Perraki, M., Apostolaki, S., Politaki, E., Kafousi, M., Stathopoulos, E.N., Stathopoulou, A., Lianidou, E., Chlouverakis, G., Sotiriou, C., Georgoulias, V. and Mavroudis, D. (2007) Different prognostic value of cytokeratin-19 mRNA positive circulating tumor cells according to estrogen receptor and HER2 status in early-stage breast cancer. Journal of Clinical Oncology, 25, 5194-5202. doi:10.1200/JCO.2007.11.7762

[28] Farmen, R.K., Nordgard, O., Gilje, B., Shammas, F.V., Kvaloy, J.T., Oltedal, S. and Heikkila, R. (2008) Bone marrow cytokeratin 19 mRNA level is an independent predictor of relapse-free survival in operable breast cancer patients. Breast Cancer Research and Treatment, 108, 251-258. doi:10.1007/s10549-007-9592-x 